\title{
International Organization of Production with Heterogeneous
}

Firms*

\author{
Erasmus K. Kersting ${ }^{\dagger}$ \\ Villanova University
}

December 2011

\begin{abstract}
This paper presents a North-South model with differentiated goods being produced in the North. Each differentiated final good requires both management and manufacturing services as inputs, and firms are heterogeneous with regard to their productivity levels in providing these inputs. Moving manufacturing to the South lowers part of a firm's variable costs. Two scenarios, which are interpreted to correspond to vertical FDI and offshoring, are investigated. In both cases there is a minimum level of management productivity required for firms to benefit from relocation of manufacturing to the South. In the case of offshoring, productivity and profit gains are relatively larger for firms with low initial manufacturing productivity. In addition, firms with very high initial productivity in both aspects choose not to offshore due to the presence of fixed costs. The model is subsequently used to examine the implications of changes in economic integration on the type of firms that exit an industry, change production location or keep manufacturing domestically.
\end{abstract}

\section{Introduction}

Globalization commentators frequently express concern about vertical specialization by firms. Firms that move production stages abroad, or offshore, are frequently depicted as causing harm to the domestic economy. But economic globalization is progressing, primarily due to a continuing drop in communication and coordination costs, which allows firms to use ever more complex production chains

\footnotetext{
${ }^{*}$ This article is based on the third chapter of my dissertation. Many thanks to Amy Glass for advice and encouragement.

†erasmus.kersting@villanova.edu
} 
that involve geographic separation. This generally depresses costs and prices in the home country, leading to firms claiming that they can only survive by geographically moving production stages. This raises questions about the consequences of decreased costs of offshoring. Allowing for heterogeneity accross firms, what are the characteristics of the firms that make use of it, and what are the general welfare implications of this facet of 'globalization'?

This paper addresses these questions by examining the production location decisions of firms that are heterogeneous across two dimensions. The production of a differentiated final good requires a unit of 'headquarter service' input and a unit of 'manufacturing' input. The amounts of labor required to produce these inputs is determined by two independent draws at the beginning of a firm's life, as in Melitz (2003). The model thus allows for differentiation between firms that have low marginal costs due to a high proficiency in management and those that have low costs because of high manufacturing productivity. While this differentiation plays no role in a world where manufacturing takes place in the same location as the headquarters, opening up the economy to the possibility of offshoring results in firms selecting themselves into different categories. Firms with a low level of management productivity will continue to choose only between domestic production and exit, depending on their draw for manufacturing productivity. It is only firms that reach a minimum level of management productivity that consider moving their production process abroad. Furthermore, of those firms with sufficiently high management productivity it is the ones with low manufacturing productivity that benefit the most from the move. As a corollary, some firms with very high initial productivity in both areas will opt to remain local producers. Comparing the case of a closed economy where manufacturing is not internationally mobile to the open case reveals the different characteristics of winners and losers. Firms that go out of business are characterized by relatively low management productivity. On the other hand, firms that have a high management productivity but very low manufacturing productivity now enter the market and produce making use of the offshoring option.

Moving the manufacturing part of the production process abroad incurs a fixed cost, but at the same time lowers variable costs. Two distinct scenarios that differ with regard to the benefits accruing to a firm from moving manufacturing to the South are examined: In the first scenario, the marginal costs after moving the manufacturing process abroad are independent of the firm's prior draw for manufacturing productivity. This scenario is interpreted to reflect the case of offshoring, in the sense that the firm's initial level of manufacturing expertise is irrelevant once that particular production stage is moved to the South and manufacturing occurs at arm's-length. In the second scenario, the marginal costs after moving the manufacturing process are proportional to the firm's manufacturing 
costs prior to the move. This case can be thought of as reflecting vertical FDI, in the sense that the firm's initial expertise in manufacturing still matters and the productivity ranking of firms remains intact even after shifting the production stage to the South. Incidentally, this scenario is isomorphic to a model where the wage rate in the South is assumed to be permanently lower, as in Grossman et al (2006).

The distinction between offshoring and vertical FDI made in this paper differs from the recent literature that models the relationship between final-good producer and supplier explicitly, focusing on relationship-specific investment (see, for example, Antràs (2003) and the references therein). In contrast to the work by Antràs and Helpman (2004), the focus of this paper does not lie in modeling the firms' decision between integration and arm's-length agreements with their suppliers. Instead, the assumption that firms are exactly equally proficient in providing management and manufacturing inputs for the production of the final good is relaxed. As a result, there are several modeling options regarding the change in manufacturing productivity (which is also the change in manufacturing marginal costs) arising from relocation to the South. The concepts of offshoring and vertical FDI are used loosely to motivate my choices among those modeling options.

Trade theory's interest in explicitly modeling differences among firms has soared in recent years. Empirical results first documented by Bernard and Jensen $(1995,1998)$ and Clerides, Lach and Tybout (1998) have shown that firms that export are significantly different form firms that do not. On average, exporting firms are larger, more productive, more capital-intensive, more technology-intensive, and pay higher wages. Later work has confirmed the robustness of these findings across countries and industries. More recently, work by Feliciano and Lipsey $(2002,2006)$ suggests that foreign-owned firms are significantly different from their domestically owned peers. Again, they are on average more productive and pay higher wages. Melitz (2003) was the first to provide a theoretical model of trade that integrated the idea of heterogeneous firms and endogenously generated the result that the most productive firms export, firms with lower productivity choose to produce only for the domestic market and firms with very low productivity immediately exit the market. Helpman, Melitz and Yeaple (2004) extend the model to incorporate horizontal foreign direct investment. In accordance with the empirical facts, the firms sort themselves according to their productivity into firms that engage in FDI, export, only produce for the domestic market or exit. Helpman et al. also provide additional empirical support for this particular ordering. In another paper, Grossman, Helpman and Szeidl (2006) study the effects of firm heterogeneity on firm choice between various integration strategies. While their 'menu' of strategies for each firm is larger because they do not only consider vertical FDI, their modeling of the 
production process differs from mine. The main difference is that firms draw one general productivity parameter for overall marginal costs and that there is no explicit modeling of a firm-specific factor that is assumed to be a key driver of vertical FDI.

The assumption of an immobile management input and a mobile manufacturing input into final good production is similar to work by Nocke and Yeaple (2007). This paper is complementary to theirs, finding a similar result that shows that the nature of firm heterogeneity (mobile vs. immobile input) matters for the firm's choice whether to offshore or not. In their paper, Nocke and Yeaple examine cross-border M\&A as a form of market access. Their specification corresponds to the case of offshoring in the present paper as it assumes lower marginal costs as the result of the cross-border merger. However, the lower the initial marginal costs of the firm, the lower the gains from engaging in cross-border M\&A, resulting in the most efficient firms remaining inactive (due to the presence of fixed costs). In the present paper, this result is obtained with offshoring, but not in the case of vertical FDI. If the relocation of the manufacturing stage always results in a drop in marginal costs, independent of your initial level of efficiency, even the most efficient firms will choose to relocate.

In its initial configuration (i.e. without the option to move production abroad) the model resembles a two-dimensional version of Melitz (2003). The equilibrium is similar - firms with draws that result in marginal costs that are too high immediately exit, the remaining ones produce. 'Opening up' the economy is interpreted to add the option to move production abroad, thereby abstracting from exporting or horizontal FDI. A firm's 'management' (or headquarters services) serves the role of a firm-specific asset that can be used to service plants abroad, as first introduced by Helpman (1984). There are no transportation costs for management, but the actual management activity has to occur in the home country.

Because firms are heterogeneous along two different dimensions, the model generates novel predictions regarding the effect of globalization on different kinds of firms. Importantly for welfare considerations, moving the manufacturing stage abroad allows high management productivity firms to enter production which otherwise would have exited due to low manufacturing productivity. On the other hand, low management productivity firms that previously would have entered now have to exit as a result of competitors choosing to relocate. While offshoring provides the biggest gains to firms that had a bad manufacturing draw initially, vertical FDI keeps the initial productivity rankings intact in the sense that it is the most productive firms (in either management or manufacturing) that see the largest growth as a result of global integration. The model predicts an ambiguous change in the number of varieties, but an increase in aggregate productivity. 
Section two of the paper will introduce the model, section three discusses the closed economy equilibrium. Section four describes the changes in the open economy and the assumptions made. Section five describes the new equilibrium. Section six compares the open and closed economy equilibria and discusses the effects of 'globalization'. Finally, section seven concludes.

\section{The Model}

\subsection{The Setup}

There are two countries, North and South, that use labor to produce goods. The South only has one sector which produces a homogeneous good. The home country (assumed to be the North) has two sectors, one of which produces the same homogeneous good while the other sector produces differentiated products. A fraction $\beta$ of income is spent on differentiated goods, while the remaining income is spent on the homogenous good, which is the numeraire. Both countries are endowed with $L$ units of labor. In what follows I will always assume that $\beta$ is small enough such that both countries produce the homogenous good and factor price equalization prevails. In fact, the common wage rate is normalized to equal one and labor is inelastically supplied.

The consumer side of the model follows the literature using the Dixit-Stiglitz (1977) differentiated goods setup. The representative consumer has a CES utility function of the form

$$
U=\left[\int_{\omega \epsilon \Omega} q(\omega)^{\rho} d \omega\right]^{1 / \rho}
$$

where $\Omega$ represents the mass of available goods. Let $Q$ be the aggregate good, so $Q \equiv U$. Furthermore, the aggregate price is given by

$$
P=\left[\int_{\omega \in \Omega} p(\omega)^{1-\sigma} d \omega\right]^{\frac{1}{1-\sigma}}
$$

Optimal consumption and expenditure decisions are given by

$$
q(\omega)=Q\left[\frac{p(\omega)}{P}\right]^{-\sigma}
$$

and

$$
r(\omega)=R\left[\frac{p(\omega)}{P}\right]^{1-\sigma}
$$


$R$ is aggregate expenditure and given by $R=P Q=\int_{\omega \epsilon \Omega} r(\omega) d \omega$.

Note that $\sigma>1$ represents the elasticity of substitution and is linked to $\rho$ by $\frac{\sigma}{1-\sigma}=\frac{1}{\rho}$. In the differentiated sector, there is a continuum of firms with mass $M$. Each firm produces a differentiated good $\omega$, resulting in monopolistic competition. The production of one unit of the final good requires two inputs which are both produced using labor, a unit of manufacturing and a unit of management. Both input units are good-specific, so manufacturing and management input by a firm that produces variety $\omega$ can only be used in the production of the final good of type $\omega$. There is no inter-firm trade in intermediate goods. The amount of labor used by each firm is a linear function of output:

$$
L=f_{D}+a_{1} q+a_{2} q
$$

Fixed cost of production are given by $f_{D}$ and are identical for each firm. $a_{1}$ represents the productivity of the firm in the production stage, since it is the number of workers needed for one unit of manufacturing input. Similarly, $a_{2}$ represents the firm's productivity in management. Note that this implies that the firm's marginal costs are equal to $a_{1}+a_{2}$. Firms are heterogeneous in the sense that each firm draws the productivity parameters from two distributions $g\left(a_{1}\right)$ and $h\left(a_{2}\right)$. The two random variables are independent. A higher productivity firm is a firm that produces a variety at a lower cost than another firm. Thus cost advantages and productivity advantages are equivalent. Cost advantages can occur in the production or manufacturing stage or both.

As is well known for these models, the firms choose a pricing rule which involves a markup over marginal cost. The markup is a function of the elasticity of substitution :

$$
p\left(a_{1}, a_{2}\right)=\frac{W \sigma}{\sigma-1}\left[a_{1}+a_{2}\right]=\frac{1}{\rho}\left[a_{1}+a_{2}\right]
$$

Here $\frac{1}{\rho}=\frac{\sigma}{\sigma-1}$ is the markup, with $\rho$ as a measure of substitutability between goods. $W$ represents the (normalized) wage rate. An advantage of this setup is that firm output, profit and revenue can all be characterized as functions of $a_{1}$ and $a_{2}$ :

$$
\begin{gathered}
r\left(a_{1}, a_{2}\right)=R[\rho P]^{\sigma-1}\left[a_{1}+a_{2}\right]^{1-\sigma} \\
\pi\left(a_{1}, a_{2}\right)=\frac{R}{\sigma}[\rho P]^{\sigma-1}\left[a_{1}+a_{2}\right]^{1-\sigma}-f_{D} \equiv B\left[a_{1}+a_{2}\right]^{1-\sigma}-f_{D}
\end{gathered}
$$

where $B \equiv \frac{R}{\sigma}[\rho P]^{\sigma-1}$ describes a demand factor that is exogenous to the individual firm's decision. 
An equilibrium is characterized by a mass $M$ of firms and distributions $\mu\left(a_{1} \mid a_{2}\right)$ and $\gamma\left(a_{2}\right)$ over supports $\left(0, \bar{a}_{1}\right)$ and $\left(0, \bar{a}_{2}\right)$, respectively ${ }^{1} . P$ is given by

$$
P=\left[\int_{0}^{\bar{a}_{2}}\left(\int_{0}^{\bar{a}_{1}} p\left(a_{1}, a_{2}\right)^{1-\sigma} M \mu\left(a_{1} \mid a_{2}\right) d a_{1}\right) \gamma\left(a_{2}\right) d a_{2}\right]^{\frac{1}{1-\sigma}}
$$

I will define an average productivity level $\widetilde{a}$ such that $P=M^{\frac{1}{1-\sigma}} p(\widetilde{a}, \widetilde{a}){ }^{2} \widetilde{a}$ represents a weighted average, where the weights are given by relative output shares:

$$
\widetilde{a}=\frac{1}{2}\left[\int_{0}^{\bar{a}_{2}}\left(\int_{0}^{\bar{a}_{1}}\left[a_{1}+a_{2}\right]^{1-\sigma} \mu\left(a_{1} \mid a_{2}\right) d a_{1}\right) \gamma\left(a_{2}\right) d a_{2}\right]^{\frac{1}{1-\sigma}}
$$

Equilibrium quantities for aggregates in the economy can now be simply displayed as functions of the weighted average productivity level $\widetilde{a} .^{3}$ Quantitatively there is no difference between the aggregate outcomes of the case of $M$ firms drawing their productivity levels randomly from the distributions given above and the case of $M$ representative, identical firms with the productivity parameter $\widetilde{a}$ for both manufacturing and management. This allows me to write aggregate revenue $R$, output $Q$ and profit $\Pi$ as a function of $\widetilde{a}$ only:

$$
\begin{gathered}
R=\int_{0}^{\bar{a}_{2}}\left(\int_{0}^{\bar{a}_{1}} r\left(a_{1}, a_{2}\right) M \mu\left(a_{1} \mid a_{2}\right) d a_{1}\right) \gamma\left(a_{2}\right) d a_{2}=M r(\widetilde{a}, \widetilde{a}) \\
Q=\frac{R}{P}=\frac{M r(\widetilde{a}, \widetilde{a})}{M^{\frac{1}{1-\sigma}} p(\widetilde{a}, \widetilde{a})}=M^{\frac{\sigma}{\sigma-1}} q(\widetilde{a}, \widetilde{a})=M^{\frac{1}{\rho}} q(\widetilde{a}, \widetilde{a}) \\
\Pi=M \pi(\widetilde{a}, \widetilde{a})
\end{gathered}
$$

Note that $q(\widetilde{a}, \widetilde{a})$ denotes the quantity produced by a firm with both productivity levels equal to $\widetilde{a}$.

\subsection{Entry and Exit of Firms}

There is an infinite number of potential entrants into the differentiated goods sector. Before entering, firms are identical. As soon as a firm decides to enter, it draws productivity parameters for its manufacturing and its management stage. The distributions for the parameters are given by $g\left(a_{1}\right)$

\footnotetext{
${ }^{1}$ The choice to describe the distribution of manufacturing productivity conditional on management productivity is an arbitrary one at this point due to the symmetry of the setup.

${ }^{2}$ This uses the pricing rule (6)

${ }^{3}$ Note that $\widetilde{a}$ represents average productivity at each production stage. Thus average productivity in producing the final good in the economy is given by $\frac{\widetilde{a}}{2}$.
} 
and $h\left(a_{2}\right)$, respectively. The supports are given by $\left(0, \bar{a}_{1}\right]$ and $\left(0, \bar{a}_{2}\right]$. The two draws are assumed to be independent. Also, entering requires the payment of a one-time fixed cost, $f_{e}$. The random draws imply that a firm does not know its own productivity before entering the industry. This appears to be a realistic assumption in accord with the empirical fact that a large number of start-ups fail soon after they enter their respective industry.

Once a firm has entered the industry and decides to stay, its productivity parameters remain constant over the lifetime of the firm.

\section{Equilibrium in the closed economy}

Without the option to move the manufacturing stage, the two stages of production of the final good are symmetric. Is is helpful to introduce $f(M C)$ to denote the distribution of the sum of $a_{1}$ and $a_{2}$, because the only value that is relevant to the decisions of the firms is total marginal cost $a_{1}+a_{2}$. Firms that draw productivity levels that result in marginal costs that are higher than some cutoff $M C^{*}$ will exit the industry, while all other firms will enter and produce.

In order to find the unique cutoff level for marginal cost $M C^{*}$, I use the following two equilibrium conditions:

$$
B\left[M C^{*}\right]^{1-\sigma}=f_{D}
$$

and

$$
\int_{0}^{M C^{*}}\left(B[a]^{1-\sigma}-f_{D}\right) f(a) d a=f_{e}
$$

(14) is the condition that ensures that the firm with marginal costs that are at the cutoff level will make zero profits. (15) ensures that expected operating profits (given by the left-hand side) are equal to the initial entry costs $f_{e}$. Figure 1 and Figure 2 show the equilibrium graphically. Note that $\sigma>1$, so that $M C^{1-\sigma}$ is actually a measure of productivity. 


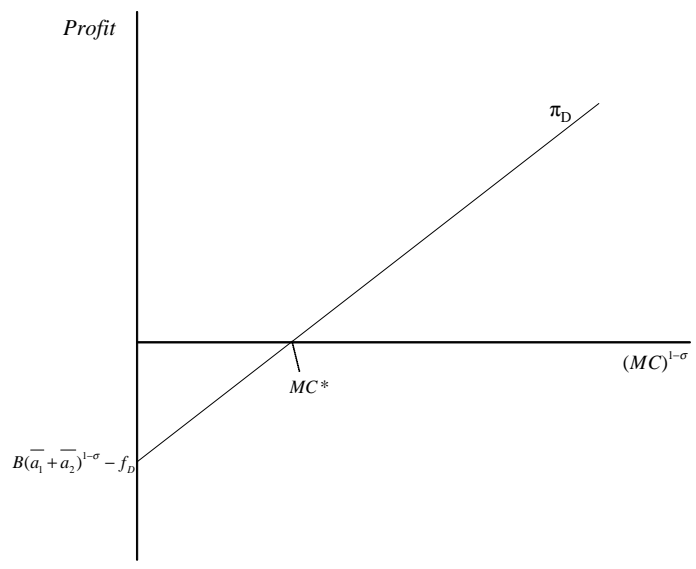

Figure 1: Profits from domestic production

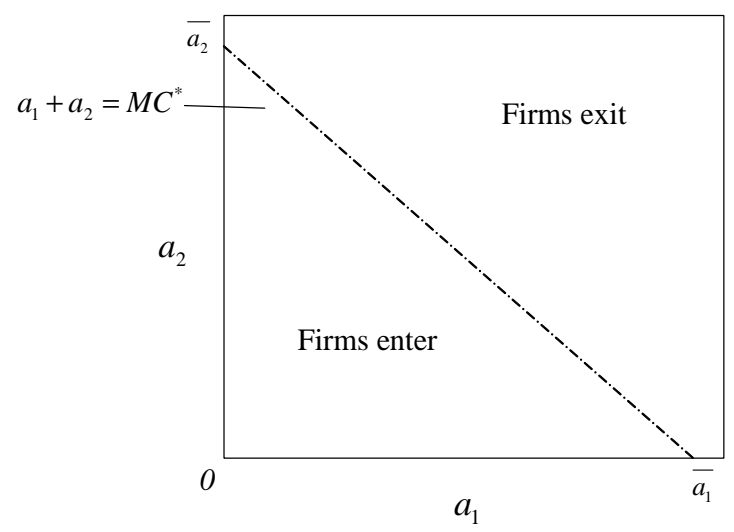

Figure 2: Exit and Entry decision as a function of the productivity draws

Note that the slope of the profit line in Figure 1 is given by $B$.

\section{4 'Opening up' the model to offshoring or vertical FDI}

In this paper, the process of globalization is studied insofar as it enables firms to move parts of their production processes into other countries. Deliberately, all of the other elements of two-country models are abstracted from. In particular, there is no costly trade between the two countries, which implies that exporting is no different from domestic sales and in the homogenous product sector it is of no relevance whether a good produced in the home country is also consumed there or possibly exported to the foreign country.

Each firm in the differentiated sector in the North is now has the choice to relocate the manufacturing production stage into the South. The management stage is tied to the North. This assumption seems plausible taking into account factors such as political pressure to keep headquarters operations 
within the home country and stylized facts that show that affiliates of U.S. multinationals have seen an increase in manufacturing employment over the last decades while manufacturing employment in the U.S. has declined.

The literature names two main factors that influence a firm's decision to relocate their production abroad. The main driver is the potential for cost savings, which are mostly brought about by lower wages and reduction in other costs (for example lower environmental standards). ${ }^{4}$ On the other hand, moving stages of the production process abroad incurs additional transportation cost, since the intermediate goods have to be shipped for further processing. I combine these two counteracting factors into one stylized effect, which is modeled as a new draw of the manufacturing productivity parameter, which replaces the 'old' draw for $a_{1}$. In other words, the decision to move the manufacturing stage is complete and final - once a firm decides to relocate manufacturing abroad, it can only choose to exit if the new draw is not high enough - it cannot move production back to the home country. Also, all of a firm's manufacturing takes place in the foreign country, once it chooses to move.

There is empirical support for the notion that firms that move parts of their production process abroad are indeed 'rewarded' by higher labor productivity in their plants. Goerg, Hanley and Strobl (2005) find that Irish plants that use a larger share of imported inputs also display higher levels of labor productivity. The effect is relatively stronger when the imported inputs are materials rather than services and for plants that are 'embedded in international markets' which means that the plant is either foreign-owned or exports its products to foreign markets.

The fact that the draw is uncertain captures the effect that the exact gains from vertical investment are often unknown to the firm prior to the undertaking. Furthermore, once a firm decides to manufacture abroad rather than domestically, the overhead costs increase from $f_{D}$ to $f_{O}$. Similar to the fixed cost for exporters in Melitz (2003) and the increased overhead costs for exporters and firms that engage in horizontal FDI in Helpman et al. (2004), opening up a new production site in a different country is bound to incur initial setup costs which do not vary with output. These setup costs can be caused by having to acquire information on foreign factor markets and comply with foreign regulations, laws etc. These costs cannot be avoided by the firm and are subject to manipulation by foreign governments. In particular, one can think of the ongoing process of global economic integration as reducing these fixed costs of outsourcing, which is a scenario that is examined later.

Obviously, the distribution of the 'new' manufacturing productivity parameters is crucial. It is

\footnotetext{
${ }^{4}$ Baldwin and Venables (2011) name both cost differences and the benefits of co-location of related production stages as benefits from vertical specialization. Due to the simple production process examined here, the latter is abstracted from.
} 
not clear whether the distribution should be correlated with a firm's initial parameter draws. Several scenarios can be envisioned:

- A firm with high management productivity may have an advantage in any area of its business and thus also in making vertical investment decisions. The consequence would be a positive correlation between the initial realization of $a_{2}$ and the newly drawn parameter $a_{1}^{N}$.

- A firm with high initial manufacturing productivity may be able to bring some of those advantages to bear in the new market. The consequence would be a positive correlation between the initial realization of $a_{1}$ and the new parameter $a_{1}^{N}$. Grossman, Helpman and Szeidl (2006) make the assumption that the wage rate in the South is lower than in the North, and that firms that relocate their production thus have lower marginal costs by the factor of $w<1$. This case can be recreated in this framework by assuming that $a_{1}^{N}=w a_{1}$.

- Setting up production in a new country is sufficiently removed from initial operations in the home country to warrant no significant correlation between a firm's initial draws and the new draw.

As a first step, potential correlations are neglected and the third option is analyzed. In addition, the distribution of the new draw is degenerate, simplifying the analysis further. In other words, relocation of the manufacturing stage always results in the same new productivity for manufacturing, which is denoted by $a_{1}^{N}$. This case of independence of the new marginal costs from initial efficiency levels of the firm corresponds most closely to offshoring. After the analysis of this case, the necessary steps to generalize the result are discussed and in what way the uncertain case will yield similar results.

\section{Equilibrium in the open economy}

\subsection{Offshoring}

This section starts with an analysis of the case of a degenerate distribution for the new productivity parameter after offshoring. By assumption, every firm that moves its manufacturing stage abroad receives a new manufacturing productivity of $a_{1}^{N}$.

The fact that offshoring can only improve the manufacturing part of the marginal cost has an immediate, interesting implication. There is now a minimum productivity level in management $a_{2}^{*}$ that a firm has to reach in order to even consider investing in production in the foreign country. $a_{2}^{*}$ is implicitly defined by: 


$$
\pi\left(a_{1}^{N}, a_{2}^{*}\right)=B\left[a_{1}^{N}+a_{2}^{*}\right]^{1-\sigma}=f_{O}
$$

Here $f_{O}>f_{D}$ represents the higher overhead for firms that offshore. Clearly, in equilibrium (for a given $B$ ) all firms with a draw for management productivity that is greater than $a_{2}^{*}$ will not consider moving production, because the (potential) gain through lower marginal costs will not compensate for the increase in overhead costs from $f_{D}$ to $f_{O}$. This splits the firms along management productivity lines:

- Firms that have drawn $a_{2}<a_{2}^{*}$ will consider offshoring and are also guaranteed to enter production (since $a_{1}^{N}$ is deterministic). However, if their draw for $a_{1}$ is close enough or even lower than $a_{1}^{N}$ they will choose not to move production because marginal cost will not fall by enough (and possibly not at all). The cutoff value for $a_{1}$ which makes these firms exactly indifferent between domestic manufacturing and offshoring is denoted by $a_{1}^{p}$.

- Firms that have drawn $a_{2}>a_{2}^{*}$ will either choose domestic production or exit. For these firms there will be a cutoff level for $a_{1}$, denoted by $a_{1}^{*}$, above which they are forced to exit altogether.

It is still true that expected operating profits have to be exactly equal to the fixed entry cost $f_{e}$ :

$$
\begin{aligned}
f_{e}= & \int_{0}^{a_{2}^{*}}\left[\int_{0}^{a_{1}^{p}}\left[B\left[a_{1}+a_{2}\right]^{1-\sigma}-f_{D}\right] d G\left(a_{1}\right)+\int_{a_{1}^{p}}^{\overline{a_{1}}}\left[B\left[a_{1}^{N}+a_{2}\right]^{1-\sigma}-f_{O}\right] d G\left(a_{1}\right)\right] d H\left(a_{2}\right) \\
& +\int_{a_{2}^{*}}^{\overline{a_{2}}}\left[\int_{0}^{a_{1}^{*}\left(a_{2}\right)}\left[B\left[a_{1}+a_{2}\right]^{1-\sigma}-f_{D}\right] d G\left(a_{1}\right)\right] d H\left(a_{2}\right)
\end{aligned}
$$

In addition, the conditions for the various cutoff levels are now given by

$$
\begin{gathered}
B\left[a_{1}^{*}\left(a_{2}\right)+a_{2}\right]^{1-\sigma}=f_{D} \\
B\left[a_{1}^{p}+a_{2}\right]^{1-\sigma}-f_{D}=B\left[a_{1}^{N}+a_{2}\right]^{1-\sigma}-f_{O} \\
B\left[a_{1}^{N}+a_{2}^{*}\right]^{1-\sigma}=f_{O}
\end{gathered}
$$

The list of unknowns is $B, a_{1}^{*}\left(a_{2}\right), a_{1}^{p}, a_{2}^{*}$ - so we have four unknowns in four equations. While the problem for firms with $a_{2}$ above $a_{2}^{*}$ is still described by a graph like Figure 1, the two profit functions 
for firms that may offshore are shown in Figure 3:

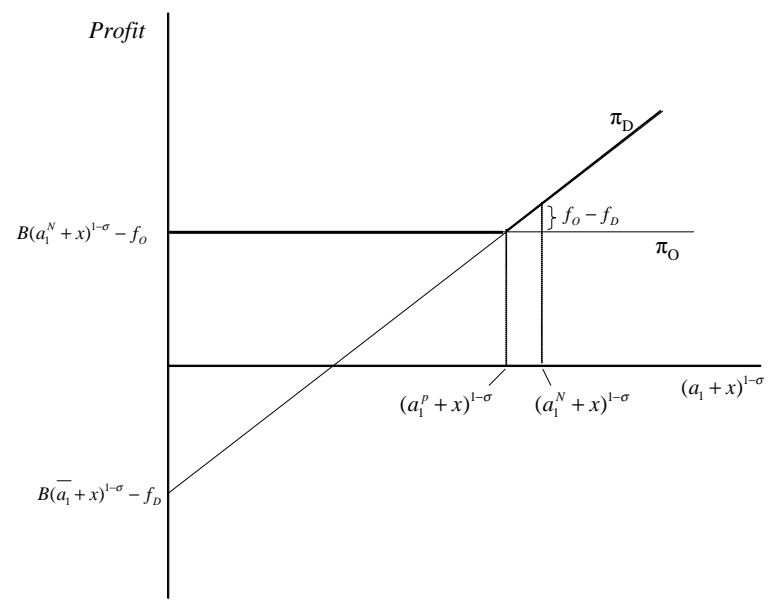

Figure 3: Profits from off-shoring and domestic production for a given $a_{2}=x$

The upper envelope of the two profit functions reflects the profits of a firm with a draw of $a_{2}=x$ as a function of $\left(a_{1}+x\right)^{1-\sigma}$. The cutoff draw for $a_{1}$ that changes the firm's decision from offshoring to domestic production is given by $a_{1}^{P}$. Note that $a_{1}^{N}<a_{1}^{P}$, implying that there is a range of firms with a draw for manufacturing productivity that can be improved upon via geographic fragmentation but that still opt to produce domestically because the increase in profit is outweighed by the loss due to the increase in overhead.

Figure 4 displays the productivity draw areas that choose the different production methods.

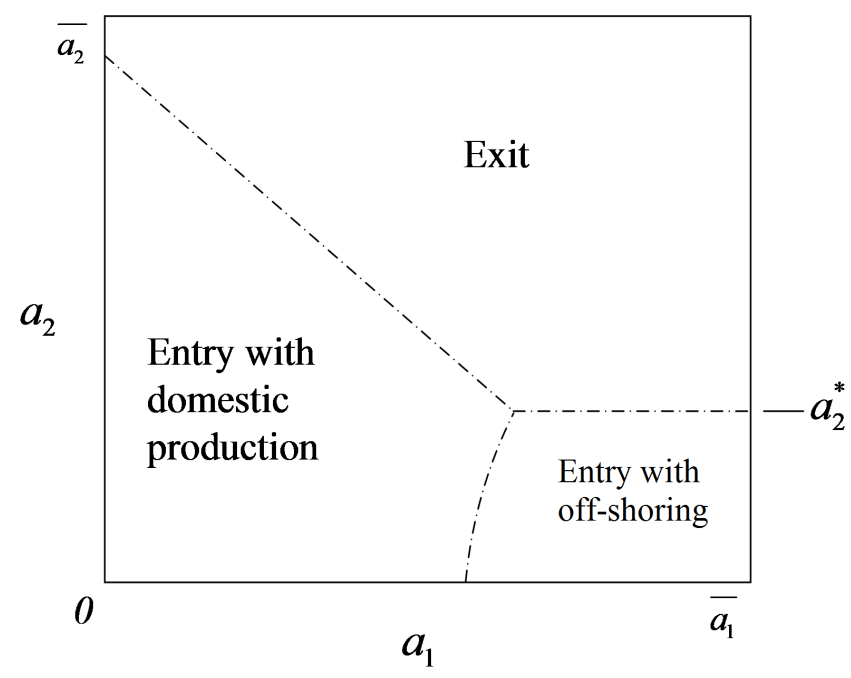

Figure 4: Firms' decision as a function of the productivity draws

Obviously the exact location of the various cutoffs depend on the chosen values, but the following qualitative results are general: 
- There will be a segment of firms that now enter production while they would have exited without the option to move production abroad. These firms are characterized by high productivity in management and very low (initial) productivity in manufacturing.

- There is a second segment of firms that switch from domestic production to vertical FDI. These firms are also characterized by high management and low manufacturing productivity.

- Finally, there are firms that opt not to change their production process. These firms already have a high level of manufacturing productivity prior to receiving the option to move production abroad.

In order to judge how well these results hold up under alternative specifications, I next examine the parallel case to Grossman et al. (2006), namely that firms that are previously good in manufacturing will continue to be good at it. The new productivity parameter will be proportional to the old one, a case which can be thought of as reflecting vertical FDI, since previously highly-efficient firms will still be highly-efficient after acquiring or opening a production site abroad.

\subsection{Vertical FDI}

As stated before, the main reasons that firms relocate parts of their production process is lower costs. The simple way in which the change in costs is modeled within this framework implies that making the assumption that the new productivity parameter $a_{1}^{N}$ is proportional to the previous manufacturing draw by the firm is in fact isomorphic to one where the productivity factor of the firm stays the same, but it pays lower wages for work done in the South. This is the assumption made in Grossman et al. (2006). So in this section, $a_{1}^{N}=w a_{1}$, with $w<1$.

Figure 5 shows the way that firms select themselves into the different groups with vertical FDI. 


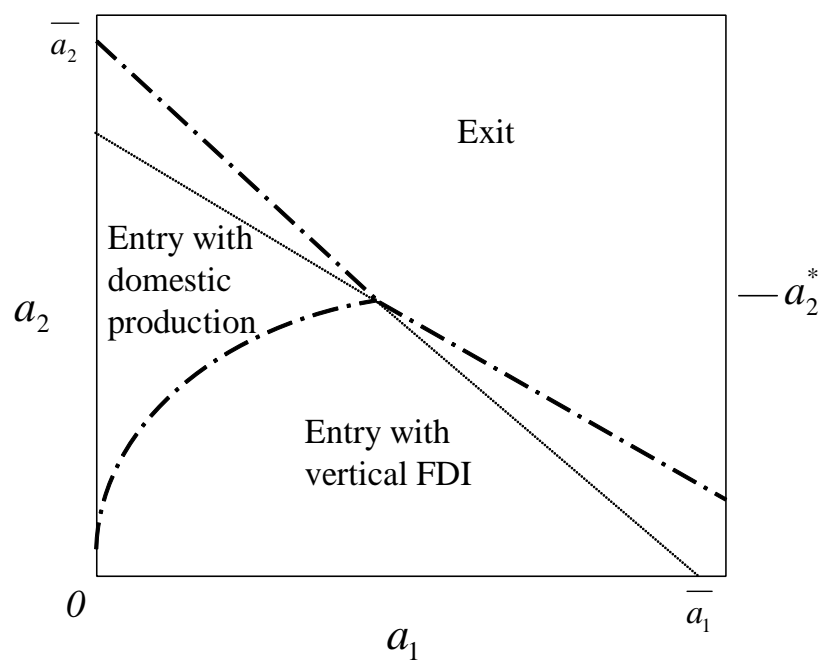

Figure 5: Equilibrium entry and FDI decisions by firms with proportional rewards to Vertical FDI

The dashed lines represent the boundaries of the regions corresponding to the three possible firm decisions. The solid lines show the way that the intersection and with it the value for $a_{2}^{*}$ is found and are given by

$$
B\left[a_{1}+a_{2}\right]^{1-\sigma}=f_{D}
$$

and

$$
B\left[w a_{1}+a_{2}\right]^{1-\sigma}=f_{O}
$$

Clearly, the slope of the line for $(21)$ in $\left(a_{1}, a_{2}\right)$ - space is exactly one, whereas it is $w<1$ for $(22)$. Also, at $a_{1}=0$, profits from domestic manufacturing are higher than those using vertical FDI by exactly $f_{O}-f_{D}$, which is positive by assumption. Given that both the intercept and the (absolute value of the) slope of the domestic manufacturing line is higher than for the vertical FDI line, the two lines must cross exactly once. At that point, firms are exactly indifferent between domestic and foreign manufacturing. Using the implicit function theorem we arrive at Proposition 1:

Proposition 1 If $w<\left(\frac{f_{D}}{f_{O}}\right)^{\frac{\sigma}{\sigma-1}}$, the line describing all points at which firms are indifferent between vertical FDI and domestic production crosses the interception of (21) and (22) from above.

Proof. See appendix.

The proposition provides the condition that needs to hold for $a_{2}^{*}$ to still represent a threshold management productivity level reaching or exceeding which is a necessary condition for a firm to consider relocation of the manufacturing stage. Intuitively, the advantage from moving manufacturing abroad needs to be significant enough, either because of a low value for $w$ or a high value for the 
relative fixed costs of domestic production and offshoring, respectively. ${ }^{5}$

While the details of the region boundaries in Figures 4 and 5 are different, the qualitative results remain similar to the more simplistic case of deterministic marginal cost awaiting firms that offshore. One difference is that in this scenario, not every firm with a management draw of $a_{2}^{*}$ or lower will automatically enter production. Those who have fairly low initial manufacturing draws may still exit now, since the rewards from FDI are proportional. Note also that it is still true that there are some 'star' firms that choose not to use the option to move the manufacturing stage because the reduction in marginal cost is not worth the increase in overhead. This is a result that is contrary to previous findings in the literature. The reason is that firms are allowed to have different productivities in their two production stages in this paper, and vertical FDI only improves one of them. This model would generate the same predictions as Grossman et al. if firms were allowed to also move their management abroad and enjoy the lower marginal cost factor $w$. However, management has to remain in the home country and forms part of a firm's marginal costs in this model. Therefore, there will always be a initial level of manufacturing productivity which is high enough to get firms to stay and manufacture domestically.

An important question is whether the mere introduction of the option to move the location of the manufacturing stage changes the values of cutoffs. Put in a different way - are there firms with management productivity below $a_{2}^{*}$ that entered the industry prior to closer economic integration but are now driven out? The next section deals with this question.

\section{The effects of opening up the economy}

\subsection{The case of two management productivity levels}

In this section I examine the effects of moving from one equilibrium to the other. Since this paper focuses on the aspects of globalization that make it easier for firms to shift parts of their production processes abroad, I examine the changes caused by giving firms the option to offshore, which they formerly did not have. As a corollary to the results of opening up to trade documented by Melitz, high productivity firms generally "win", while low productivity firms that did produce without offshoring may now be driven out of the industry.

In order to clarify the exposition and generate some analytical results, I return to the degenerate

\footnotetext{
${ }^{5}$ Recall that a low $w$ will mean a large decrease in marginal costs for a firm. Similarly, a value of $f_{O}$ that is only slightly higher than $f_{D}$ will result in many firms to choose vertical FDI.
} 
distribution for $a_{1}^{N}$ and also assume that there are only two levels of productivity in management in differentiated goods sector of the home economy, $a_{2}^{L}$ and $a_{2}^{H}$. Note that low values represent low costs, so that $a_{2}^{L}$ is the 'better' productivity draw.

For comparison purposes, let us remember the equilibrium in this case for an economy without the offshoring option. There is a cutoff level for marginal cost $M C^{*}$, and thus the $a_{1}$-cutoff level between production and exit for firms that have drawn $a_{2}^{L}$ for management productivity is given by

$$
a_{1}^{L^{*}}=M C^{*}-a_{2}^{L}
$$

Similarly, the cutoff for the low management productivity firms is

$$
a_{1}^{H^{*}}=M C^{*}-a_{2}^{H}
$$

Clearly, we have $a_{1}^{L^{*}}>a_{1}^{H^{*}}$. There is also a demand factor that the firms take as given, $B \equiv \frac{R}{\sigma}[\rho P]^{\sigma-1}$. The equilibrium conditions are

$$
\begin{gathered}
B\left(a_{1}^{H^{*}}+a_{2}^{H}\right)^{1-\sigma}=f_{D} \\
B\left(a_{1}^{L^{*}}+a_{2}^{L}\right)^{1-\sigma}=f_{D} \\
\frac{1}{2}\left[\int_{0}^{a_{1}^{H^{*}}}\left(B\left(a_{1}+a_{2}^{H}\right)^{1-\sigma}-f_{D}\right) d G\left(a_{1}\right)\right]+\frac{1}{2}\left[\int_{0}^{a_{1}^{L^{*}}}\left(B\left(a_{1}+a_{2}^{L}\right)^{1-\sigma}-f_{D}\right) d G\left(a_{1}\right)\right]=f_{e}
\end{gathered}
$$

In the last condition we assume that the two draws for management productivity are equally probable. Given values for $a_{2}^{L}, a_{2}^{H}, f_{D}, f_{e}$ and $G\left(a_{1}\right)$ this system of three equations can be solved for $B, a_{1}^{H^{*}}$ and $a_{1}^{L^{*}}$.

Now we introduce the option to offshore. As we saw in Figure 5, firms that are productive enough to benefit from offshoring (in this scenario that is firms that draw $a_{2}^{L}$ ) will always enter production, the question is only whether they produce locally or abroad. For low productivity firms the question is still only between exit and entry. So the conditions are now given by

$$
\begin{gathered}
B\left(a_{1}^{H^{*}}+a_{2}^{H}\right)^{1-\sigma}=f_{D} \\
B\left[\left(a_{1}^{N}+a_{2}^{L}\right)^{1-\sigma}-\left(a_{1}^{P}+a_{2}^{L}\right)^{1-\sigma}\right]=f_{O}-f_{D}
\end{gathered}
$$




$$
\begin{aligned}
f_{e}= & \frac{1}{2}\left[\int_{0}^{a_{1}^{P}}\left(B\left(a_{1}+a_{2}^{L}\right)^{1-\sigma}-f_{D}\right) d G\left(a_{1}\right)+\left(1-G\left(a_{1}^{P}\right)\right)\left(B\left(a_{1}^{N}+a_{2}^{L}\right)^{1-\sigma}-f_{O}\right)\right] \\
+ & \frac{1}{2}\left[\int_{0}^{a_{1}^{H^{*}}}\left(B\left(a_{1}+a_{2}^{H}\right)^{1-\sigma}-f_{D}\right) d G\left(a_{1}\right)\right]
\end{aligned}
$$

Furthermore, we have the assumptions

$$
B\left(a_{2}^{H}\right)^{1-\sigma}<f_{O}
$$

and

$$
B\left(a_{1}^{N}+a_{2}^{L}\right)^{1-\sigma}>f_{O}
$$

These conditions lead us directly to Proposition 2:

Proposition 2 The introduction of the option to offshore results in a lower cutoff level $a_{1}^{H^{*}}$, meaning that the least productive firms are driven out.

Proof. See Appendix.

Intuitively, expected profits ex-ante must stay the same since they are tied down by the fixed entry cost $f_{e}$. Since drawing a high management productivity value now guarantees production, expected profits conditional on having drawn $a_{2}^{L}$ increase and average productivity $\widetilde{a}$ does, as well. Thus it has to be the case that expected profits conditional on having drawn $a_{2}^{H}$ decrease, and this is achieved by decreasing the cutoff value and thus making it less likely for firms that have drawn $a_{2}^{H}$ to enter production to begin with. Note that this also has a positive effect on $\widetilde{a}$, which therefore unambiguously rises compared to the old scenario.

A corollary of Proposition one is that the new demand level $B$ is lower than before introducing the option of vertical foreign investment. This can only be due to two possible factors, a decrease in nominal expenditure $R$ or a decrease in the price level $P$. A decrease in $P$ can be due to a decrease in the prices charged by individual firms or due to a decrease in the total number of firms entering. $R$ in these models is set by the size of the economy, which has not changed. Thus it has to be the case that $P$ has decreased.

Proposition 3 The introduction of the option to offshore results in every firm having the same or a higher total productivity level.

Proof. For the firms drawing $a_{2}^{H}$ this follows directly from proposition one. For the firms drawing $a_{2}^{L}$, note that the firm that before was the marginal firm with productivity levels $\left(a_{1}^{L^{*} \text { old }}, a_{2}^{L}\right)$ now makes a 
loss, due to the drop in B. Therefore, it chooses to offshore. This proves that $a_{1}^{p}<a_{1}^{L^{*} \text { old }}$. So every firm with a draw of $a_{1}^{p}$ or higher will end up with manufacturing marginal cost of $a_{1}^{N}$ due to production relocation, which is equivalent to an increase in productivity. Finally, high management productivity firms with productivity draws $a_{1}<a_{1}^{p}$ will have the same marginal cost as without offshoring.

Proposition 3 shows that each firm in the industry charges the same or a lower price than before. This leaves open the question of the total number of available varieties. Does the exodus of firms with low management productivity result in an overall decrease in available varieties, or is the increased number of firms with high management productivity, that can now stay in business because they are able to shift production abroad, enough to compensate or even exceed that number?

Unfortunately, without further information regarding the distribution of productivity levels this question is impossible to answer. It reduces to the question whether $G\left(a_{1}^{H^{*}}\right.$ old $)-G\left(a_{1}^{H^{*}}\right.$ new $)$, which represents the mass of exiting firms, is greater than $1-G\left(a_{1}^{L^{*}}\right.$ old $)$, which represents the firms that are now able to enter.

\subsection{Continuous support for both distributions of productivity levels}

The previous subsection analyzed the case of only two possible outcomes for the management productivity draw due to analytical tractability. In this subsection I discuss what the likely consequences of relaxing this assumption would be. For that reason, I now assume that the support for the distribution of $a_{2}$ is given by $\left(0, \overline{a_{2}}\right]$.

Recall that as soon as there is continuous support, there is also a cutoff level for $a_{2}$ which splits the firms into those that choose between offhsoring and domestic production and those that only choose between exiting and domestic production.

$$
a_{2}^{*}=\left(\frac{f_{O}}{B}\right)^{\frac{1}{1-\sigma}}-a_{1}^{N}
$$

Figure 6 shows the effect of introducing the option of offshoring on the domestic differentiated products sector. 


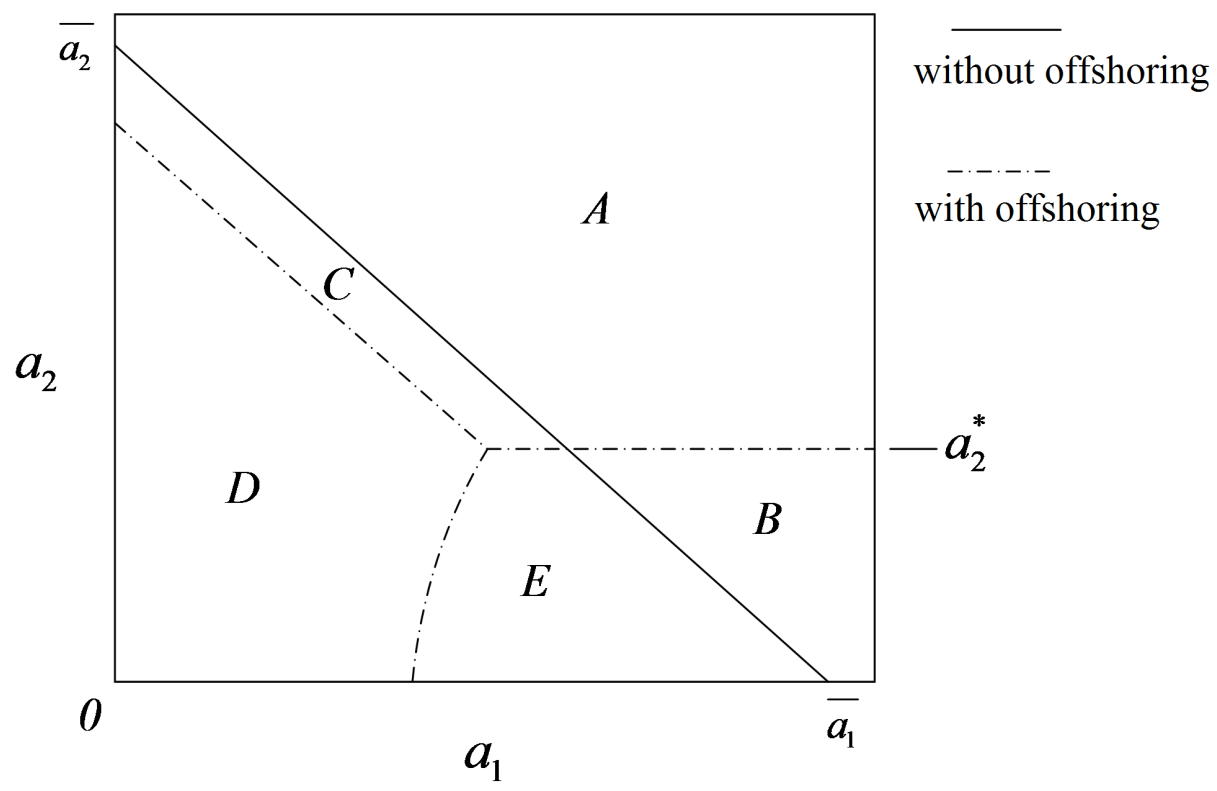

Figure 6: Production decision with and without offshoring by firms in the differentiated goods sector as a function of the productivity draws

In the initial equilibrium, firms with draws in the areas $\mathrm{A}$ and $\mathrm{B}$ will exit, all other firms enter the industry and produce. Introducing the productivity gains of offshoring will have different effects depending on whether the firm is above or below the management cutoff level $a_{2}^{*}$ : For firms with productivity levels in the area $\mathrm{C}$, the drop in the exogenous demand factor $B$ results in negative profits, so that these firms are driven out. Firms in area D are firms that do not change, but for different reasons. Those that are above $a_{2}^{*}$ do not choose to offshore because it will not generate positive profits, independent on how much their manufacturing productivity might improve. The firms in area $\mathrm{D}$ below $a_{2}^{*}$ do not choose to offshore because the gains in manufacturing productivity are not worth the increase in overhead costs. Clearly, an increase in the productivity level achieved by offshoring would shift the boundary between $\mathrm{D}$ and $\mathrm{E}$ to the left, at the same time as it would raise $a_{2}^{*}$ and shift the general cutoff line to the left due to the indirect effect on $B$. If wage cost differences between the North and the South are significant, the process of globalization will result in a relatively larger number of firms to exit and a relatively smaller number of firms keeping their manufacturing stage in the North.

Finally, firms in area B are clearly the ones benefiting the most from the opportunity to move production abroad. They would not have been able to produce in the initial equilibrium due to too high manufacturing costs. Their high management productivity, however, results in them being able to take advantage of globalization by entering the industry and making positive profits. 
Summarizing, the rise of offshoring causes the overall demand factor $B$ to fall, since differentiated products can now be produced at lower costs on average. This causes profits for all firms that do not move production abroad to fall. Firms in the area $\mathrm{C}$ in Figure 5 exit production. Firms in area E switch from domestic manufacturing to foreign based manufacturing, thereby raising their profits. Finally firms in area B raise their profits dramatically, because they have no prospects of entry without the possibly of production stage relocation.

Note the difference to the basic result emphasized by Melitz: In his paper, 'opening up' the economy corresponds to firms gaining the opportunity to export. As a result, the more productive a firm is, the more it gains from trade. Here, it is not the firms that are most productive overall that gain the most, but instead it is firms that are very productive in the management stage but initially have relatively high manufacturing costs, resulting in a large gain from moving the manufacturing stage abroad.

\subsection{Effects of a continuing process of globalization}

Generally, global economic integration is not seen as occurring in discrete jumps, but rather as a gradual process. Thus it is of interest to examine the changes in Figure 6 that would occur if 'globalization'related parameters were to continue changing.

Given that the new draw for manufacturing productivity captures a host of different costs related to moving a production process abroad, we study the case of a decrease in $a_{1}^{N}$. Even though factor price equalization may be expected to erode labor cost differences over time, transportation and communication costs fall, as well, which makes the case that relocation of manufacturing processes becomes more attractive as globalization continues a plausible one.

A drop in $a_{1}^{N}$ will cause more firms to shift their manufacturing abroad (see Figure 7).

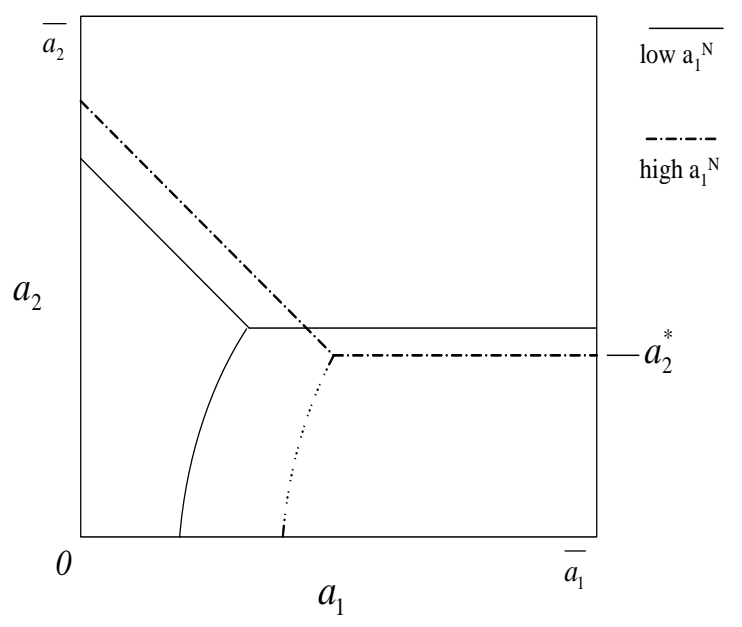


Figure 7: Changes in firms' production decisions due to a drop in $a_{1}^{N}$

Note that the firms in the triangular area above the (new) value for $a_{2}^{*}$ are left with relatively high marginal costs compared to the firms with higher management productivity, many of which now choose to move manufacturing abroad. This corresponds to high prices and thus to low output, so those firms will in general be rather small. So the model displays one of the obvious consequences of economic integration, which is to drive out smaller firms while generating opportunities for firms with high management productivity. The model shares this particular feature with the original model by Melitz.

Next we can also envision a reduction in $f_{O}$, which corresponds to the costs of setting up a production site in a foreign country approaching the corresponding costs in the home country. Inspection of $(33)$ reveals that a decrease in $f_{O}$ will also move $a_{2}^{*}$ upwards, resulting in ceteris paribus more firms choosing to move manufacturing abroad. At the same time, the trade-off between domestic production and FDI for those firms below $a_{2}^{*}$ will move to the left, so that the resulting change in the will be very similar to the one depicted in Figure 7. Note that the upwards movement of $a_{2}^{*}$ is limited by the simultaneous decrease in $B$ due to the increase in overall average productivity. In other words, even with a 'high degree of globalization' we don't expect to see $a_{2}^{*}$ to be close to $\overline{a_{2}}$, meaning that most firms can engage in vertical FDI and produce.

Summarizing, a continuing process of globalization can be examined in this model via two different comparative statics exercises. As it turns out, both the reduction in overhead for production oversees and an increase in the productivity gains achieved via vertical FDI have similar effects. Small firms with low management productivity are driven out of production, while the number of firms that engage in vertical FDI increases. Eventually, firms that retain manufacturing in the home country will be characterized by very high productivity in both management and manufacturing - all other firms will have either exited or shifted the manufacturing stage. During this adjustment process, it is mainly firms that shift their manufacturing stages that grow (meaning their output and profits increase). Firms that retain domestic manufacturing, on the other hand, see a decrease in profits due to the ever more competitive nature of the monopolistic competition and the subsequent decline in the demand factor $B$.

By definition the model cannot address aspects of unemployment and changes in the composition of the workforce. In addition, it does not explicitly model changes in factor prices. The literature on this aspect of offshoring is understandably vast, see for example Venables (1999), Deardorff (2001) or Kohler (2004). In this model, there is only one production factor, so all kinds of labor are homogenous 
in this model. Also, employment is always full and is given exogenously by the size of the world (which is $2 L$ ). However, we can note that domestic firms that engage in offshoring or vertical FDI will expand output and thus require more workers in the management sector. Also, employment in the homogenous goods sector in the South decreases, which means that the domestic homogenous sector has to increase, in order to produce the same amount of goods globally (recall that the fractions of expenditure spent on the various types of goods are given by $\beta$ and $1-\beta$ and constant.) So the implied change in the transition of the workforce in the home country is a flow from manufacturing jobs into management jobs but also into the homogenous goods sector.

\subsection{Relaxing the assumption of a degenerate distribution of $a_{1}^{N}$}

Most parts of the analysis up to this point were obviously facilitated by the assumption of offshoring having a known, deterministic benefit in form of a new and higher productivity measure for the manufacturing stage. A more realistic characterization would be another uncertain draw, with bad outcomes that could feasibly lead to exit of firms that have made the decision to move production abroad. For example, while there may be wage differences the firm was hoping to take advantage of, the costs of transportation and coordination with foreign officials may exceed expectations, leading to less cost saving that initially anticipated. For this scenario to leave the qualitative results derived up to this point unchanged, we only need to make the following assumptions. The continued validity of the results hinges on ex-post average productivity of firms with a given management draw $a_{2}<a_{2}^{*}$ (where $a_{2}^{*}$ is now computed using $E\left[B\left(a_{1}^{N}+a_{2}^{*}\right)^{1-\sigma}\right]=f_{O}$, assuming risk-neutral firms) being higher than the corresponding value in the economy without offshoring. But this has to hold, because only firms with a given management $\operatorname{draw} a_{2}<a_{2}^{*}$ with $B^{\text {new }}\left(a_{1}^{N}+a_{2}\right)^{1-\sigma} \geq f_{O}$ will stay in the industry after the second draw. But since $B^{\text {new }}<B^{\text {old }}$ and $B^{\text {old }}\left(a_{1}^{*}+a_{2}\right)=f_{D}$, it has to be true that $a_{1}^{N}<a_{1}^{*}$. This guarantees that in fact the ex-post average productivity levels for firms with management draw $a_{2}<a_{2}^{*}$ is higher than in the scenario without vertical FDI. ${ }^{6}$

\footnotetext{
${ }^{6}$ Note that firms can exit immediately after observing the second draw, without incurring additional costs. While it would be interesting to include the resources lost to unsuccessful ventures abroad, this particular complication is left for future work.
} 
The new conditions corresponding to (17) - (20) are given by:

$$
\begin{gathered}
f_{e}=\int_{0}^{a_{2}^{*}}\left[\int_{0}^{a_{1}^{p}}\left[B\left[a_{1}+a_{2}\right]^{1-\sigma}-f_{D}\right] d G\left(a_{1}\right)+\int_{a_{1}^{p}}^{\overline{a_{1}}}\left(B E\left[\left[a_{1}^{N}+a_{2}\right]^{1-\sigma}\right]-f_{O}\right) d G\left(a_{1}\right)\right] d H\left(a_{2}\right) \\
+\int_{a_{2}^{*}}^{\overline{a_{2}}}\left[\int_{0}^{a_{1}^{*}\left(a_{2}\right)}\left[B\left[a_{1}+a_{2}\right]^{1-\sigma}-f_{D}\right] d G\left(a_{1}\right)\right] d H\left(a_{2}\right) \\
B\left[a_{1}^{*}\left(a_{2}\right)+a_{2}\right]^{1-\sigma}=f_{D} \\
B\left[a_{1}^{p}+a_{2}\right]^{1-\sigma}-f_{D}=B E\left[\left[a_{1}^{N}+a_{2}\right]^{1-\sigma}\right]-f_{O} \\
B E\left[\left[a_{1}^{N}+a_{2}^{*}\right]^{1-\sigma}\right]=f_{O}
\end{gathered}
$$

The possibility of a bad draw introduces another way that the option of offshoring leads to increased exit by low productivity firms: While all firms below $a_{2}^{*}$ will choose to offshore (because their expected profits cover the overhead $f_{O}$ ), firms whose level of management productivity is high are ex-ante more likely to stay in business after the realization of the FDI draw. This effect is similar to the one documented in the vertical FDI case of section 5.2.

Overall, the main result remains: By causing an overall decrease in average marginal cost in the differentiated goods sector, the option to move manufacturing stages abroad leads to welfare gains. The exact channel through which welfare increases is the decline in the price index, while the amount of total nominal expenditure remains fixed at the level of the total labor force (of both countries combined, since foreign country consumers also consume differentiated goods).

\section{Conclusions}

This paper constructs a heterogeneous firms model that allows for two distinct production stages that are required to produce the final good. While trade is costless and the paper thus abstracts form the efficiency gains caused by inter-industry redistribution documented by Melitz (2003), global economic integration is still shown to lead to efficiency gains by allowing firms to move their production stages into the foreign country, which, while being costly, is assumed to lead to productivity gains at the firm level. 
Interestingly, the firms that benefit most from this kind of economic integration are not those with the lowest marginal costs ex-ante. Instead, it is firms that are very productive in executing the task that has to remain in the home country (management) but initially not so productive in the manufacturing stage that experience the largest increases in profits. The details of these effects depend on various assumptions regarding the distributions of the productivity parameters and their potential correlation. Two cases are emphasized: offshoring is assumed to result in a new marginal cost draw for manufacturing that is independent of a firm's initial manufacturing draw. Vertical FDI, on the other hand, lowers marginal manufacturing costs proportionally to the firm's inital costs. As long as moving the manufacturing stage to the South is costly, there will be firms in equilibrium that choose to keep manufacturing in the North. As 'globalization' progresses, these firms will enjoy lower profits, because the overall decrease in production costs depresses the price level. At a late stage, only few, large, high manufacturing and management productivity firms will remain that still locate the manufacturing stage of production in the home country.

The analysis is deliberately stylized, which prohibits detailed results with respect to the exact nature of the efficiency gains from offshoring. A more detailed look at welfare consequences from the change in number of varieties or the loss of resources due to unsuccessful offshoring projects is left for future research.

\section{References}

[1] Antràs, P., (2003), "Firms, Contracts, and Trade Structure," Quarterly Journal of Economics, $118,1375-1418$.

[2] Antràs, P. and Elhanan Helpman, (2004), "Global Sourcing," Journal of Political Economy, Vol. $112,3,552-580$.

[3] Baldwin, R. and A. J. Venables (2011), "Relocating the Value Chain: offshoring and Agglomeration in the Global Economy," Discussion Paper Series, No. 544, University of Oxford.

[4] Bernard, A.B., Jensen, J.B., (1995): "Exporters, jobs, and wages in U.S. Manufacturing, 19761987," Bookings Papers on Economic Activity, Microeconomics. Washington DC.

[5] Bernard, A.B., Jensen, J.B., (1999): "Exceptional exporter performance: cause, effect or both?," Journal of International Economics, Vol. 47, 1-25. 
[6] Clerides, S.K., Lach, S., Tybout, J.R., (1998): "Is Learning by Exporting Important? MicroDynamic Evidence from Colombia, Mexico, and Morocco," The Quarterly Journal of Economics, Vol. 113, 3, 903-947.

[7] Deardorff, A., (2001), "Fragmentation in Simple Trade Models," North American Journal of Economics and Finance 12, 121-137.

[8] Dixit, A.K., Stiglitz, J.E., (1977): "Monopolistic Competition and Optimum Product Diversity," The American Economic Review, Vol. 67, 3, 297-308.

[9] Feliciano, Zadia and Robert E. Lipsey (2002), "Foreign Firms and Indonesian Manufacturing Wages: An Analysis with Panel Data," NBER Working Paper No. 9417.

[10] Feliciano, Zadia and Robert E. Lipsey (2006), "Foreign Ownership, Wages, and Wage Changes in the United States, 1987-1992", Contemporary Economic Policy, 24: 74-91.

[11] Goerg, H., Hanley, A. and Eric Strobl (2005), "Productivity effects of international outsourcing: Evidence from plant level data," manuscript.

[12] Grossman, G.M., Helpman, E. and Adam Szeidl (2006), "Optimal integration strategies for the multinational firm," Journal of International Economics, 70, 216-238.

[13] Helpman, E., (1984), "A Simple Theory of International Trade with Multinational Corporations," The Journal of Political Economy, 92, 3, 451-471.

[14] Helpman, E., Melitz, M.J., Yeaple, S.R. (2004), "Export versus FDI with Heterogeneous Firms," The American Economic Review, Vol. 94, 1, 300-316.

[15] Hummels, D., Ishii, J. and K.M. Yi (2001), "The nature and growth of vertical specialization in world trade," Journal of International Economics, Vol. 54, 1, 75-96.

[16] Kohler, W., (2004), "Aspects of International Fragmentation," Review of International Economics, $12,5,793-816$.

[17] Melitz, M.J., (2003): "The Impact of Trade on Intra-Industry Reallocations and Aggregate Industry Productivity," Econometrica, Vol. 71, 6, 1695-1725.

[18] Nocke, V. and S. Yeaple (2007), "Cross-border mergers and acquisitions vs. greenfield foreign direct investment: The role of firm heterogeneity," Journal of International Economics, Vol. 72, 336-365. 
[19] Venables, A.J. (1999), "Fragmentation and Multinational Production," European Economic Review 43, 935-45.

\section{A Appendix}

Proof of Proposition 1:

The implicit function defining $a_{1}^{*}$ and $a_{2}^{*}$ is given by

$$
B\left[w a_{1}+a_{2}\right]^{1-\sigma}-f_{O}=B\left[a_{1}+a_{2}\right]^{1-\sigma}-f_{D}
$$

The solution where both profit levels are exactly zero is known:

$$
\begin{aligned}
& \left(a_{1}^{*}+a_{2}^{*}\right)=\left(\frac{f_{D}}{B}\right)^{\frac{1}{1-\sigma}} \\
& \left(w a_{1}^{*}+a_{2}^{*}\right)=\left(\frac{f_{O}}{B}\right)^{\frac{1}{1-\sigma}}
\end{aligned}
$$

Using the Implicit Function Theorem we get

$$
\begin{aligned}
a_{1}^{\prime}\left(a_{2}\right) & =-\left.\frac{\left[(1-\sigma)\left(w a_{1}+a_{2}\right)^{-\sigma}-(1-\sigma)\left(a_{1}+a_{2}\right)^{-\sigma}\right]}{\left[(1-\sigma) w\left(w a_{1}+a_{2}\right)^{-\sigma}-(1-\sigma)\left(a_{1}+a_{2}\right)^{-\sigma}\right]}\right|^{a_{1}=a_{1}^{*}, a_{2}=a_{2}^{*}} \\
& =-\left[\frac{f_{O}^{\frac{\sigma}{\sigma-1}}-f_{D}^{\frac{\sigma}{\sigma-1}}}{w f_{O}^{\frac{\sigma}{\sigma-1}}-f_{D}^{\frac{\sigma}{\sigma-1}}}\right]
\end{aligned}
$$

so for $a_{1}$ to fall as $a_{2}$ falls (which is what is require for Figure 5 to be reflecting the equilibrium) we require

$$
w<\left(\frac{f_{D}}{f_{O}}\right)^{\frac{\sigma}{\sigma-1}}
$$

Proof of Proposition 2:

By contradiction: Suppose the cutoff level stayed the same. Then $B$ must also be the same. Then using (27) and (30) we get

$$
\begin{aligned}
& \frac{1}{2}\left[\int_{0}^{a_{1}^{L^{*}}}\left(B\left(a_{1}+a_{2}^{L}\right)^{1-\sigma}-f_{D}\right) d G\left(a_{1}\right)\right] \\
= & \frac{1}{2}\left[\int_{0}^{a_{1}^{P}}\left(B\left(a_{1}+a_{2}^{L}\right)^{1-\sigma}-f_{D}\right) d G\left(a_{1}\right)+\left(1-G\left(a_{1}^{P}\right)\right)\left(B\left(a_{1}^{N}+a_{2}^{L}\right)^{1-\sigma}-f_{O}\right)\right]
\end{aligned}
$$


or, using the fact that with unchanged $B$ it must be the case that $a_{1}^{L^{*}}>a_{1}^{P}$,

$$
\int_{a_{1}^{P}}^{a_{1}^{L^{*}}}\left(B\left(a_{1}+a_{2}^{L}\right)^{1-\sigma}-f_{D}\right) d G\left(a_{1}\right)=\left[\left(1-G\left(a_{1}^{P}\right)\right)\left(B\left(a_{1}^{N}+a_{2}^{L}\right)^{1-\sigma}-f_{O}\right)\right]
$$

Close inspection reveals the contradiction: The integral on the left hand side must be smaller because we know that $B\left(a_{1}^{L^{*}}+a_{2}^{L}\right)^{1-\sigma}-f_{D}=0$ and $B\left(a_{1}^{P}+a_{2}^{L}\right)^{1-\sigma}-f_{D}=B\left(a_{1}^{N}+a_{2}^{L}\right)^{1-\sigma}-f_{O}$. Now suppose the new cutoff level is higher, $a_{1}^{H^{*}}$ new $>a_{1}^{H^{*} \text { old }}$. This implies that the demand factor must be higher, as well: $B^{\text {new }}>B^{\text {old }}$. Again, using (27) and (30) we get

$$
\begin{aligned}
& {\left[\int_{0}^{a_{1}^{H^{*} \text { old }}}\left(B^{\text {old }}\left(a_{1}+a_{2}^{H}\right)^{1-\sigma}-f_{D}\right) d G\left(a_{1}\right)\right]+\left[\int_{0}^{a_{1}^{L^{*}}}\left(B^{\text {old }}\left(a_{1}+a_{2}^{L}\right)^{1-\sigma}-f_{D}\right) d G\left(a_{1}\right)\right] } \\
= & {\left[\int_{0}^{a_{1}^{P}}\left(B^{\text {new }}\left(a_{1}+a_{2}^{L}\right)^{1-\sigma}-f_{D}\right) d G\left(a_{1}\right)+\left(1-G\left(a_{1}^{P}\right)\right)\left(B^{\text {new }}\left(a_{1}^{N}+a_{2}^{L}\right)^{1-\sigma}-f_{O}\right)\right] } \\
& +\left[\int_{0}^{a_{1}^{H^{*} \text { new }}}\left(B^{\text {new }}\left(a_{1}+a_{2}^{H}\right)^{1-\sigma}-f_{D}\right) d G\left(a_{1}\right)\right]
\end{aligned}
$$

An increase in $B$ combined with an increase in the cutoff level results in $\int_{0}^{a_{1}^{H^{*}} \text { old }}\left(B^{\text {old }}\left(a_{1}+a_{2}^{H}\right)^{1-\sigma}-f_{D}\right) d G\left(a_{1}\right)<$ $\int_{0}^{a_{1}^{H^{*} \text { new }}}\left(B^{\text {new }}\left(a_{1}+a_{2}^{H}\right)^{1-\sigma}-f_{D}\right) d G\left(a_{1}\right)$. But then it must be true that

$$
\begin{aligned}
\int_{0}^{a_{1}^{L^{*}}}\left(B^{\text {old }}\left(a_{1}+a_{2}^{L}\right)^{1-\sigma}-f_{D}\right) d G\left(a_{1}\right)> & \int_{0}^{a_{1}^{P}}\left(B^{\text {new }}\left(a_{1}+a_{2}^{L}\right)^{1-\sigma}-f_{D}\right) d G\left(a_{1}\right) \\
& +\left(1-G\left(a_{1}^{P}\right)\right)\left(B^{\text {new }}\left(a_{1}^{N}+a_{2}^{L}\right)^{1-\sigma}-f_{O}\right)
\end{aligned}
$$

For the same reasons as in the previous case this forms a contradiction. 